\title{
Efecto del Tiempo de Almacenamiento sobre las Propiedades Fisicoquímicas, Probióticas y Antioxidantes de Yogurt Saborizado con Mortiño (Vaccinium meridionale Sw)
}

\author{
Isabel C. Zapata(1), Uriel Sepúlveda-Valencia ${ }^{(2)}$ y Benjamín A. Rojano(3) \\ (1) Universidad Católica de Oriente, Facultad de Ingeniería. Rionegro-Colombia. \\ (e-mail: izapata@uco.edu.co) \\ (2) Universidad Nacional de Colombia, Facultad de ciencias Agrarias. Sede Medellín, Medellín-Colombia. \\ (e-mail: labplatec_med@unal.edu.co) \\ (3) Universidad Nacional de Colombia, Laboratorio de Ciencia de Alimentos, Facultad de Ciencias, Sede \\ Medellín, Medellín-Colombia. (e-mail: brojano@unal.edu.co) \\ * autor a quien debe ser dirigida la correspondencia
}

Recibido Jul. 1, 2014; Aceptado Sep. 8, 2014; Versión final recibida Oct. 30, 2014

\section{Resumen}

En este estudio, se evalúo las propiedades fisicoquímicas, probióticas y antioxidantes en el tiempo, del yogurt de mortiño (Vaccinium meridionale Swartz) elaborado a partir de dos concentraciones de almíbar de fruta $(15$ y $20 \%)$. En las propiedades físico-químicas se aprecia descenso del pH, aumento de acidez titulable y disminución de la concentración de sacarosa. Los resultados de la estabilidad probiótica revelaron que la concentración de $10^{6} \mathrm{UFC} / \mathrm{mL}$ se mantiene durante los 16 primeros días de almacenamiento como lo recomienda la norma para productos probióticos. Los resultados de actividad antioxidante, del contenido de fenoles totales y de antocianinas totales, revelaron que existe un incremento de éstas entre los primeros 8 y 12 días de almacenamiento y luego un descenso. Se concluye que el producto puede ser considerado como un alimento nutracéutico.

\section{Effect of Storage Time on the Physicochemical, Probiotic and Antioxidant Properties of Yogurt Flavored with Colombian Berry (Vaccinium meridionale Sw)}

\begin{abstract}
In this study, the physicochemical, probiotic and antioxidant properties in time, of yogurt prepared with Colombian berry syrup (Vaccinium meridionale Swartz) at two concentrations (15 and $20 \%$ of fruit). The physicochemical changes experienced by the product during storage were the $\mathrm{pH}$ decrease, increasing acidity values and decreased sucrose concentration. The results of the probiotic stability for all samples revealed that the concentration of $10^{6} \mathrm{CFU} / \mathrm{mL}$ is stable for the first 16 days of storage as recommended by the standards for the description of probiotic products. The results of antioxidant activity, of total phenols content and of anthocyanins, revealed an increase of these between the first 8 and 12 days of storage and after that a decline of these characteristics. It is concluded that the product can be considered as a nutraceutical food.
\end{abstract}




\section{INTRODUCCIÓN}

En la industria alimenticia se han comenzado a marcar tendencias sobre el consumo de alimentos saludables, por lo que es relevante el desarrollo de nuevos productos que no solo otorguen propiedades nutricionales sino farmacéuticas al consumidor. Existen múltiples investigaciones que reportan propiedades antioxidantes, antimicrobiológicas, antiinflamatorias y anticarcinogénicas de fuentes naturales alimenticias y aunque los yogures no son estrictamente productos naturales, la fortificación con extractos de frutas pueden catalogarlo como tal (Illupapalayan et al., 2014; Sah et al., 2014).

El yogurt es una bebida láctea obtenida a partir de la fermentación de la lactosa para producir ácido láctico y otras estructuras químicas. La fermentación se realiza por la acción de dos bacterias ácido lácticas: Streptococcus thermophillus y Lactobacillus delbrueckii ssp. Bulgaricus; que no solo son responsables de la fermentación sino que son viables y abundantes en el producto final donde funcionan como probióticos y proveen beneficios a la salud. (Rodriguez et al., 2013). En el proceso de fermentación de la leche los cultivos bacterianos forman un coágulo homogéneo, liso y viscoso y con las características deseadas de $\mathrm{pH}$, sabor y aroma. Los métodos de fabricación varían considerablemente no obstante existen condiciones generales para la obtención del producto final como son la preparación de los ingredientes y la leche, el precalentamiento, la homogenización, el tratamiento térmico, el enfriamiento hasta la temperatura de inoculación y la siembra del cultivo iniciado (Abdel-Rahman et al., 2013).

En los últimos años se han implementado etapas adicionales como la incorporación de compuestos bioactivos, por ejemplo antioxidantes y probioticos. Los probioticos son microorganismos vivos con efectos fisiopatológicos positivos. Las investigaciones al respecto sugieren que estos últimos pueden contribuir al equilibrio de la microbiota intestinal del huésped y potenciar el sistema inmunitario, tienen efecto antimicrobiano contra bacterias patógenas, efecto antiviral, son resistentes a rangos muy amplios de $\mathrm{pH}$ y temperatura, se cree que además mejora la digestión y la tolerancia a la leche. La adición de fruta también es una alternativa adicional y tiene como objetivo saborizar el producto y otorgarle resultados nutracéuticos colaterales, pues se sabe que las frutas se caracterizan por aportar cantidades significativas de fibra $(0.5-2$ $\mathrm{g}$ de fibra total $/ 100 \mathrm{~g}$ de fruta fresca), una gran variedad de vitaminas y minerales, principalmente vitamina $\mathrm{C}$, un bajo contenido en grasa y son fuente casi exclusiva de compuestos polifenólicos que actúan como antioxidantes y que se han relacionado con diversos efectos beneficiosos para la salud. De otro lado la adición de probióticos o microorganismos vivos que permanecen activos en el intestino ejercen importantes efectos fisiológicos, pueden contribuir al equilibrio de la microbiota intestinal del huésped y potenciar el sistema inmunitario (Petti y Scully, 2009).

El mortiño, agraz o arándano (Vaccinium meridonale Sw) es una planta de la familia Ericaceae. El mortiño es conocida en los andes Colombianos como fruta del bosque, y ha despertado un interés agroindustrial debido al alto contenido de polifenoles especialmente antocianinas como delfinidina y cianidina, además ácidos fenólicos como ferúlico, cafeico y clorogénico; metabolitos secundarios responsables de su elevada actividad antioxidante, que ha presentado efectos cardioprotectores y antiproliferativos (Gaviria et al., 2012, Lopera et al., 2013, Maldonado et al., 2014).

La elaboración de un producto nutracéutico necesita una buena composición de metabolitos secundarios responsables de sus propiedades fisicoquímicas, y funcionales y además condiciones de almacenamiento que permitan una estabilidad del mismo y que minimicen las consecuencias del deterioro provocado por las cascadas químicas y bioquímicas que se van desarrollando en la matriz alimentaria. Es importante entonces determinar la proporción de dichos cambios con el fin de fijar el tiempo óptimo de consumo y las condiciones de almacenamiento (Illupapalayam et al., 2014). Este trabajo tiene como objetivo evaluar los cambios fisicoquímicos, antioxidantes y probióticos del yogurt de mortiño preparado a dos concentraciones de fruta, para concluir sobre su funcionalidad y momento óptimo de consumo.

\section{MATERIALES Y MÉTODOS}

Se describe con algún detalle las materias primas utilizadas, la elaboración del yogurt, la preparación y adición del almíbar de mortiño al yogurt, las propiedades fisicoquímicas de los materiales, la evaluación sensorial y las propiedades probióticas y propiedades antioxidantes del producto.

\section{Materias primas}

Hay tres materiales principales en la elaboración del yogurt saborizado: la leche, el cultivo iniciador y probiótico y los frutos de mortiño: 
Leche: La leche fue suministrada por la planta de leches de la Universidad Nacional de Colombia- Sede Medellín (Colombia), quienes se encargaron de verificar el cumplimiento de los parámetros de calidad para la recepción de leches crudas en centros de acopio.

Cultivo Iniciador y probiótico: El cultivo iniciador utilizado fue Streptococcus thermophillus, lactobacillus del bruecki, subsp bulgaricus cepa comercial liofilizada (Mediterranea biotecnologie) y almacenada a $-20^{\circ} \mathrm{C}$ hasta su uso. El Cultivo probiótico utilizado fue Lactobacillus casei, cepa comercial liofilizada (Danisco) y almacenada $\mathrm{a}-20^{\circ} \mathrm{C}$ hasta su uso.

Frutos de Mortiño: Los frutos de mortiño (Vaccinium meridionale Sw.) se obtuvieron en el mercado local del municipio del Retiro - Antioquia (Colombia), se seleccionaron de forma aleatoria asegurando madurez de cosecha y ningún daño fisiológico aparente, posteriormente fueron llevados al Laboratorio Ciencia de los Alimentos de la Universidad Nacional de Colombia - Sede Medellín y almacenados a $4^{\circ} \mathrm{C}$ hasta su preparación.

Elaboración del yogurt batido: La leche se pasterizó a $85^{\circ} \mathrm{C}$ por 15 minutos en pasterizador Greamery package, se enfrió hasta $4^{\circ} \mathrm{C}$ mediante el uso de un intercambiador de calor (Cherry burrel c) y se homogenizo a 1500 psi (St regis). Se adicionó el cultivo iniciador en un relación de acuerdo a recomendación del fabricante, 30 minutos después se agregó el cultivo probiótico en una concentración de $12 \%(\mathrm{p} / \mathrm{v})$, y la mezcla se incubó a $41,5^{\circ} \mathrm{C}$ en baño con agua termostatizado, hasta alcanzar un valor de acidez titulable igual a 0,55 \% expresado como equivalentes de ácido láctico como recomiendan los autores (Sah et al., 2014). Posteriormente se llevó a refrigeración $\left(4^{\circ} \mathrm{C}\right)$ y tras 12 horas, se agitó la mezcla fermentada y se adicionó el almíbar de fruta preparado como se describe a continuación.

\section{Preparación y adición del almíbar de mortiño (Vaccinium meridionale Sw) al yogurt}

Previo a la elaboración del almíbar de fruta, $17 \mathrm{Kg}$ de frutos de Mortiño fueron lavados y desinfectados con hipoclorito de sodio 100 ppm. Para la preparación del almíbar se adicionaron $6 \mathrm{~kg}$ de agua y $4 \mathrm{~kg}$ de sacarosa comercial, posteriormente la mezcla se calentó y se agitó hasta la evaporación del $40 \%$ del agua inicial, tiempo tras el cual se adicionaron los $17 \mathrm{~kg}$ de mortiño previamente adecuados, se continuó con agitación lenta manteniendo la temperatura entre 70 y $80^{\circ} \mathrm{C}$ durante 3 horas más. Finalmente se suplemento el yogur previamente elaborado con el almíbar logrando concentraciones finales del 15 y el 20 $\% \mathrm{p} / \mathrm{v}$ denominadas tratamiento 1 y tratamiento 2 respectivamente, el control se considera el yogurt sin adición de almíbar de fruta. Tanto el control como los tratamientos se almacenaron a $4^{\circ} \mathrm{C}$ por 20 días, tiempo durante el cual se realizaron los respectivos análisis.

\section{Propiedades fisicoquímicas.}

Todas las propiedades fisicoquímicas fueron determinadas en los días 0, 4, 8, 12,16 y 20 de almacenamiento bajo condiciones de refrigeración $\left(4^{\circ} \mathrm{C}\right)$.

pH: Para la medición del pH se usó un potenciómetro digital (Metrohm 744, Suiza), previamente calibrado con buffer $\mathrm{pH} 7$ y buffer $\mathrm{pH}$ 4. El electrodo se introdujo en la muestra y se leyó el pH, las determinaciones se hicieron por triplicado, entre cada determinación el electrodo se lavó con agua destilada y se secó cuidadosamente.

Acidez titulable: La acidez titulable se determinó por triplicado por el método del AOAC 942.15, 1996. La determinación se hizo por titulación con una solución valorada de hidróxido de sodio $0.1 \mathrm{~N}$, se transfirieron cantidades conocidas de la muestra a un matraz Erlenmeyer y se adicionó $2 \mathrm{~mL}$ de agua destilada, más 2 gotas de solución de fenolftaleína. Posteriormente se tituló la muestra hasta que se mantuvo el vire al color rosa por 1 minuto. La acidez titulable es expresada como porcentaje de ácido láctico.

Contenido de azúcares: La determinación de azúcares totales se realiza por HPLC utilizando un cromatógrafo líquido Shimadzu, LC-20AD, equipado con un auto inyector SIL-20ª /HT, un módulo de comunicación CBM-20 ${ }^{a}$ y un detector con arreglo de fotodiodos (PDA) SPD-M20A, según el protocolo modificado de Eyéghé-Bickong et al., 2012. La separación de sacarosa, glucosa y fructosa se llevó a cabo en una columna Bio-Rad, utilizando como fase móvil ácido sulfúrico $5 \mathrm{mM}$. La identificación de los picos se realizó comparando con estándares de sacarosa, glucosa y fructosa.

\section{Evaluación sensorial.}

Se realizó una prueba de nivel de agrado con algunas modificaciones (Watts et al., 1992) en un total de 90 panelistas para evaluar el nivel de aceptación del consumidor frente al yogurt con almíbar en los días 0,8 y 16 de almacenamiento bajo refrigeración. Cada panelista recibe las dos muestras (15 y $20 \%$ p/v de almíbar). 
El orden de presentación de las muestras fue aleatorio para cada miembro evaluador y la prueba se realizó en un cuarto iluminado.

\section{Propiedades probioticas}

Las propiedades probioticas fueron determinadas en los días 0, 8 y 16 de almacenamiento bajo condiciones de refrigeración $\left(4^{\circ} \mathrm{C}\right)$. Para el análisis de viabilidad celular (probiótico), se llevó a cabo el recuento de microorganismos en placa en agar MRS.

Para la evaluación de lactobacilos, se tomaron $1 \mathrm{~mL}$ de las muestras y se ajustaron hasta $10 \mathrm{~mL}$ con agua peptonada (dilución $10^{-1}$ ), luego $1 \mathrm{ml}$ de esta dilución y se llevó a otros $10 \mathrm{ml}$ con agua peptonada (dilución $10^{-2}$ ), se repitió este procedimiento hasta obtener diluciones seriadas de hasta $\left(10^{-6}\right)$. Para el montaje $1 \mathrm{ml}$ de la cada dilución fue adicionado a una caja de Petri y $15 \mathrm{~mL}$ del medio de cultivo fundido y enfriado a 45$50 \stackrel{\circ}{\circ}$ fueron adicionados se mezcló por rotación hasta la solidificación. La incubación se realizó en atmósfera anaeróbica con 5-10\% $\mathrm{CO}_{2}$, a $35^{\circ} \mathrm{C}$ durante 5 días. Para verificar el crecimiento de Lactobacilos se observaron colonias generalmente pequeñas, blancas-grisáceas, lisas o rugosas y se realizó el conteo de Unidades Formadoras de colonias / mL de muestra. (Sakai et al., 2010)

\section{Propiedades antioxidantes}

Todas las propiedades antioxidantes fueron determinadas en los días 0, 4, 8, 12, 16 y 20 de almacenamiento bajo condiciones de refrigeración $\left(4^{\circ} \mathrm{C}\right)$.

Actividad atrapadora del radical libre $D P P H$. Se empleó el método de Brand-Williams con algunas modificaciones (Gaviria et al., 2012). En un tubo de ensayo, se adicionaron $10 \mathrm{~mL}$ de la fase acuosa de la bebida y $990 \mathrm{~mL}$ de una solución de DPPH. Como referencia se usó la misma cantidad de DPPH y $10 \mathrm{~mL}$ del solvente de la muestra (agua). Se evaluó la capacidad antioxidante por medio de la disminución en la absorbancia luego de 30 minutos de reacción, a una longitud de onda de $517 \mathrm{~nm}$. Se calculó el porcentaje de inhibición del radical y los resultados se expresaron como valores TEAC (Trolox Equivalent Antioxidant Capacity) ( $\mu \mathrm{mol}$ de trolox/L muestra) mediante la construcción de una curva patrón, usando como antioxidante Trolox. Los análisis se realizaron por triplicado.

\section{FRAP (Capacidad reductora).}

Se realizó según el método de Benzie y Strain (Zapata et al., 2013). Se utiliza una solución de TPTZ, muestra y de agua destilada. Luego de $30 \mathrm{~min}$ se lee la absorbancia a una longitud de onda de $593 \mathrm{~nm}$. Se construye la curva de referencia usando ácido ascórbico. Las actividades de las muestras se expresaron como AEAC (Capacidad Antioxidante en Equivalentes de Ácido Ascórbico: mg de ácido ascórbico / L muestra).

Método ORAC (Oxygen radical absorbance capacity). El procedimiento experimental empleó Trolox como estándar y condiciones controladas de temperatura a $37^{\circ} \mathrm{C}$. El ensayo se determinó diluyendo el Trolox en buffer fosfato $75 \mathrm{mM}(\mathrm{pH} 7.4)$ y en agua-acetona $(1: 1, \mathrm{v} / \mathrm{v})$ para ORAC-H y en $\beta$-metilciclodextrina al $7 \%$ para ORAC-L. Las lecturas se realizaron a una $\lambda$ de excitación de $493 \mathrm{~nm}$, y $\lambda$ de emisión de $515 \mathrm{~nm}$. Para el desarrollo de la técnica se prepararon $3 \mathrm{~mL}$ de la siguiente solución: $21 \mathrm{~mL}$ de una solución de fluoresceína $10 \mathrm{Mm}, 2899 \mathrm{~mL}$ de buffer fosfato, $50 \mathrm{~mL}$ de AAPH $600 \mathrm{mM}$ y $30 \mathrm{~mL}$ de la fase acuosa/lipofílica de la bebida o Trolox $500 \mathrm{mM}$ (estándar). El efecto protector del antioxidante, se calculó usando las diferencias de áreas bajo la curva de decaimiento de la fluoresceína entre el blanco y la muestra, y se comparó contra la curva del Trolox. Los resultados fueron expresados como valores TEAC ( $\mu \mathrm{mol}$ de trolox/L muestra), de acuerdo con la siguiente ecuación (Zapata et al 2013):

valorORAC $=\left(\frac{A U C_{\text {muestra }}-A U C_{\text {control }}}{A U C_{\text {trolox }}-A U C_{\text {control }}}\right) \cdot f[$ trolox $]$

Donde AUC es el área bajo la curva y f es el factor de dilución de los extractos.

\section{Contenido de metabolitos antioxidantes}

Determinación de fenoles totales. La determinación de fenoles se realizó por el método colorimétrico de Folin-Ciocalteu (Zapata et al., 2013).En un tubo de reacción se adicionaron $50 \mathrm{~mL}$ de la fase acuosa de la bebida, $425 \mathrm{~mL}$ de agua destilada y $125 \mathrm{~mL}$ del reactivo Folin-Ciocalteu. Se agitó, y luego se dejó en reposo por 6 minutos. Posteriormente, se adicionaron $400 \mathrm{~mL}$ de $\mathrm{Na}_{2} \mathrm{CO}_{3}$ al $7.1 \%$. Después de 1 hora en la 
oscuridad, se leyó la absorbancia a $760 \mathrm{~nm}$. Se construyó una curva patrón usando como estándar ácido gálico. Los análisis se realizaron por triplicado y los resultados se expresaron como mg de ácido gálico/L muestra.

Antocianinas totales. Las antocianinas totales se determinan mediante el método diferencial de $\mathrm{pH}$ (Gaviria et al 2012). La absorbancia es medida en un espectrofotómetro JeanWay $6405 \mathrm{UV} /$ Vis a $530 \mathrm{~nm}$ y $700 \mathrm{~nm}$ en buffers $\mathrm{pH} 1,0$ y 4,5, usando $\mathrm{A}=[(\mathrm{A} 530-\mathrm{A} 700) \mathrm{pH} 1.0-(\mathrm{A} 530-\mathrm{A} 700) \mathrm{pH} 4.5]$, con un coeficiente de extinción molar para el cianidin -3 - glucósido de 26900. Los resultados son expresados como miligramos equivalentes de cianidin -3 - glucósido por $L$ de muestra.

Contenido de ácido ascórbico: El contenido de ácido ascórbico se cuantifica usando la metodología de Novakova et al., 2008, con algunas modificaciones, por medio de cromatografía líquida de alta resolución (HPLC), usando un detector UV a $245 \mathrm{~nm}$, una columna C-8 y como fase móvil, ácido fórmico $0.1 \%$.

Análisis estadístico: Todos los experimentos fueron realizados por triplicado y los valores medios y sus desviaciones estándar reportados. Diferencias estadísticamente significativas entre tratamientos fueron estimadas a través de un análisis de varianza (ANOVA) aplicando el modelo de medidas repetidas (MR) con un nivel de significancia del $95 \%(p<0.05)$ para todas las variables evaluadas. Este análisis fue realizado usando el paquete estadístico Rstudio (R-3.0.3, Windows FAQ) y las gráficas fueron realizadas por Microsoft Excel 2013 (Microsoft, USA).

Para el análisis de datos de la prueba sensorial, las categorías se convierten en puntajes numéricos del 1 al 6 , donde 1 - Me gusta muchísimo y 6 - Me disgusta muchísimo. Los puntajes numéricos para cada muestra, se tabulan y analizan utilizando análisis de varianza (ANOVA), para determinar si existen diferencias significativas

\section{RESULTADOS Y DISCUSIÓN}

\section{Propiedades Fisicoquímicas}

La fortificación del yogurt con fruta provocó la disminución en los valores de $\mathrm{pH}$ e incremento los valores de acidez del producto. El pH del yogurt control decreció desde 4,04 hasta 3,90 cuando se fortificó con 15\% de almíbar de mortiño y desde 4,04 hasta 3,87 cuando se fortificó con $20 \%$ de almíbar de mortiño. Este comportamiento es de esperarse, pues se sabe que las frutas poseen un gran contenido de ácidos orgánicos que acidifican el medio donde estas se adicionen. Para el mortiño (Vaccinium meridionale Sw) se reporta contenidos de ácido cítrico, ácido málico y ácido ascórbico de 1250, 950 y 8 mg/100g de fruta respectivamente (Maldonado et al., 2014). La evaluación de la estabilidad fisicoquímica reveló que el pH de la muestra control y de las muestras tratadas decrecía durante los 20 días de almacenamiento a tasas relativamente similares, $0,015 \pm 0,001$ unidades de $\mathrm{pH}$ /día (Figura 1a). Estos resultados reflejan la presencia de actividad metabólica celular en el almacenamiento.

Las bacterias ácido lácticas por ejemplo tienen la característica de producir ácidos que incrementan eventualmente la concentración de $\mathrm{H}^{+}$en el medio, se ha demostrado además que el cultivo iniciador de Lactobacillus spp tiene actividad proteolítica, y genera aminoácidos y pequeños péptidos ácidos que inducen a la reducción del $\mathrm{pH}$, además $S$. thermophilus genera metabolitos como el ácido fórmico y el dióxido de carbono que también reducen el valor de $\mathrm{pH}$ (Ostlie et al., 2003). La aparición de ácidos orgánicos libres se corroboró mediante la cuantificación de acidez en el tiempo. (Figura 1b).

Los resultados obtenidos son concordantes con los de otros autores quienes establecen que los procesos bioquímicos que desarrollan los microorganismos dentro de productos alimenticios tiene como resultados la generación y acumulación de ácido acético, acetaldehído, ácido fórmico, ácido láctico, $\mathrm{CO}_{2}$, aminoácidos y péptidos. (Amirdivani y Baba, 2011).

\section{Contenido de azúcares}

Se midió el contenido de azúcares (glucosa, fructosa y sacarosa) en el tiempo, los resultados revelaron que existe un incremento de monosacáridos reductores tipo glucosa y fructosa con la consecuente desaparición de su disacárido constituyente sacarosa durante el tiempo (figura 2). En el almacenamiento es de esperarse la aparición de azúcares simples ya que los polisacáridos de la muestra están sometidos a la acción enzimática de las BAL (amilasas, sacarasas, etc), esto genera la escisión homolítica de enlaces y la consecuente conversión de los polisacáridos a sus respectivas unidades monoméricas. Adicionalmente la disminución del pH en el tiempo favorece el crecimiento de los cultivos iniciadores y con ello su actividad metabólica. Algunos se han referido a esto como "edulcorante en almacenamiento" (Eissa et al., 2011) 

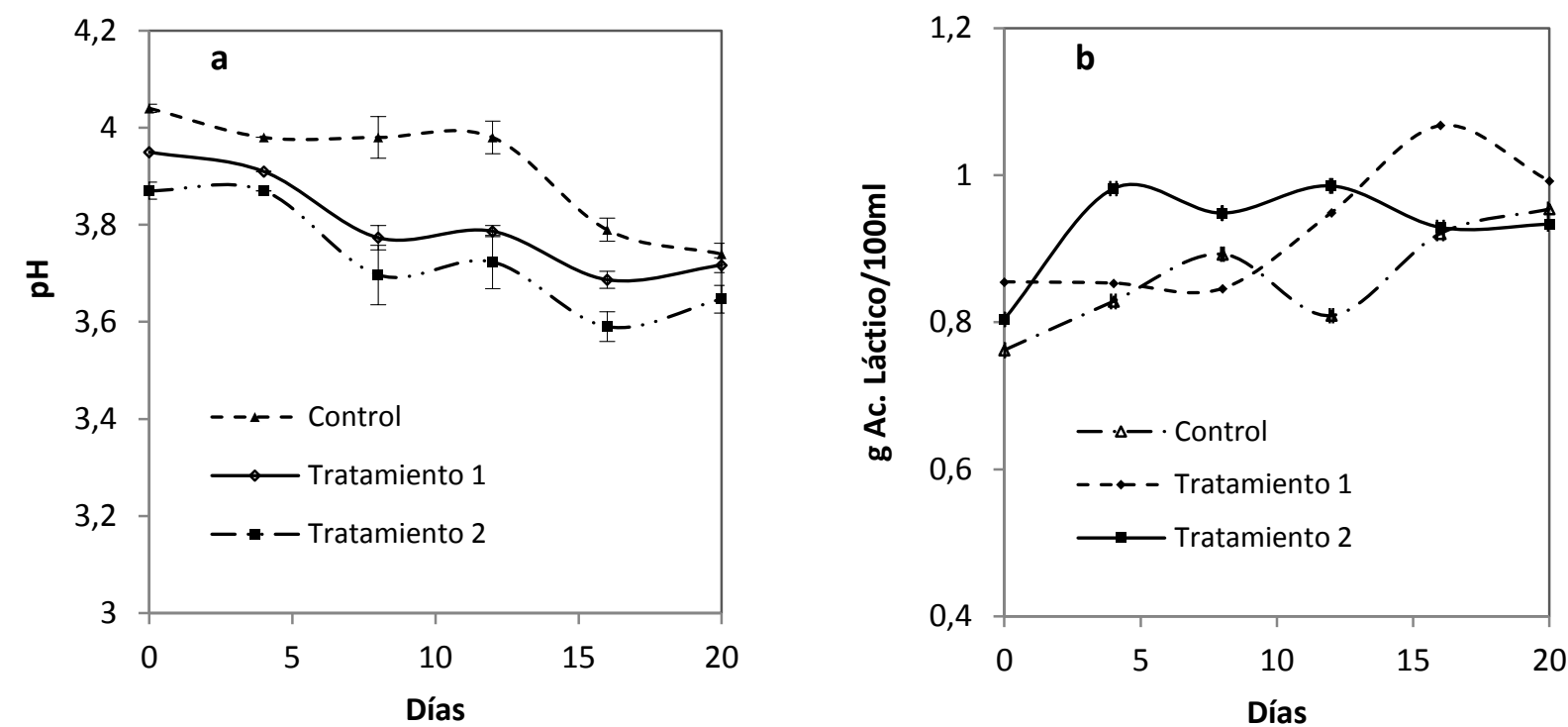

Fig. 1. Medida del a) $\mathrm{pH}$ y b) Acidez titulable del yogurt control, tratamiento 1 y tratamiento 2 , durante 20 días de almacenamiento a $4^{\circ} \mathrm{C}$
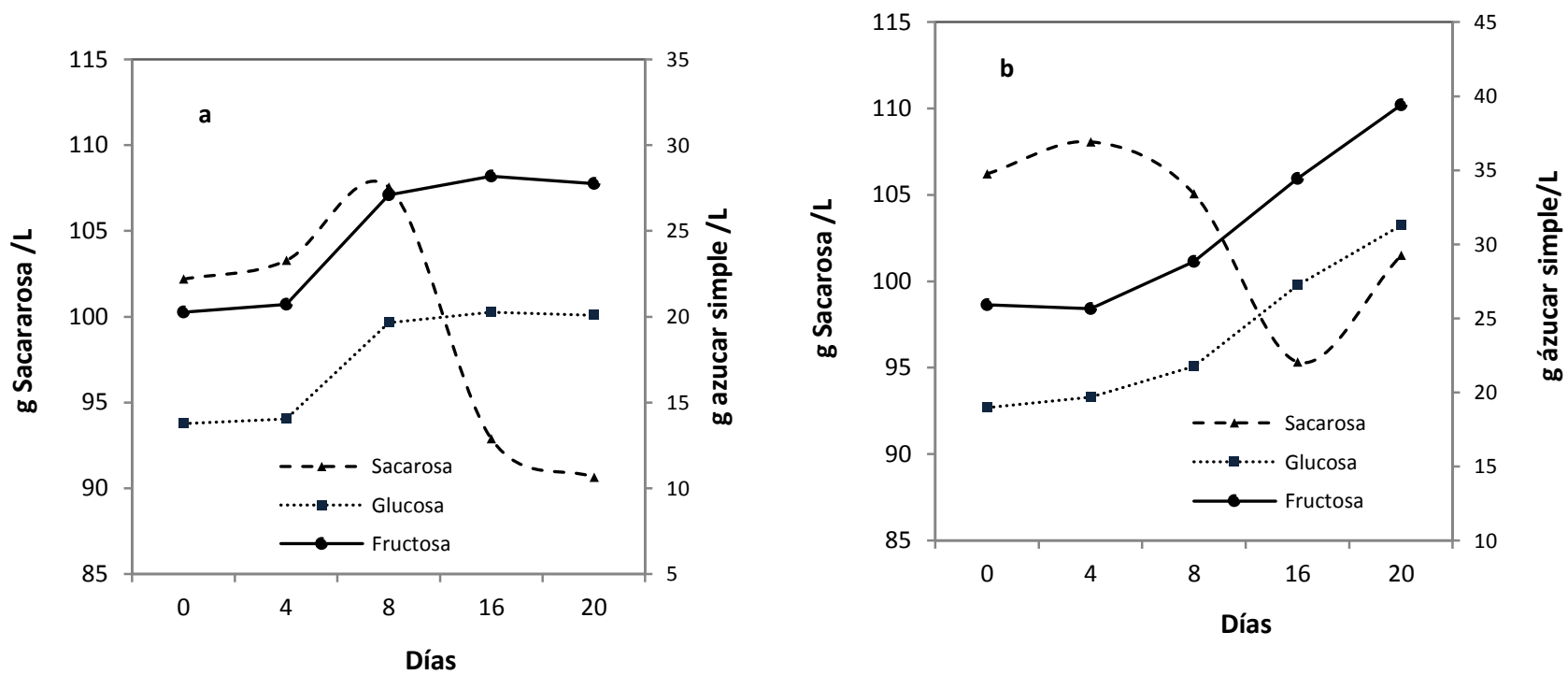

Fig. 2. Medida del contenido sacarosa, glucosa y fructosa en el yogurt con a) tratamiento 1 y b) Tratamiento 2, durante 20 de almacenamiento a $4^{\circ} \mathrm{C}$

\section{Prueba de nivel de agrado}

La prueba de aceptación realizada a 90 panelistas les exigía evaluar las características sensoriales de las muestras tratadas a través del tiempo y concluir de acuerdo al gusto. El yogurt fortificado con $20 \%$ de fruta (tratamiento 2) presentó para todos los tiempos mayor aceptación que el yogurt fortificado con $15 \%$ de fruta (tratamiento 1), resultado que es de esperarse considerando que la adición de fruta tiene como principal objetivo saborizar y mejorar la apariencia del producto. Los panelistas fueron reiterativos al mencionar que la presencia de trozos de frutas en el producto más concentrado atraía de manera particular su gusto.

El yogurt fortificado con $15 \%$ de almíbar de mortiño redujo su aceptación al público a través del tiempo pasando de una calificación completamente positiva (100\%) a una calificación medianamente positiva (75\%), hecho que podría explicarse si se observa la disminución en los valores de pH, el incremento en los valores de acidez titulable y la disminución en la cantidad de sacarosa en el mismo intervalo de tiempo, estos valores señalan que al cabo de los días el producto no solo es más ácido sino menos dulce, contribuyendo al posible rechazo. El yogurt fortificado con $20 \%$ de almíbar de mortiño presentó un leve decremento en el parámetro de aceptación y en general fue de gran acogida, los panelistas aseguraron sentirse muy atraídos por la apariencia del producto, hecho que los motivó a calificarlo positivamente incluso cuando el sabor había variado. 

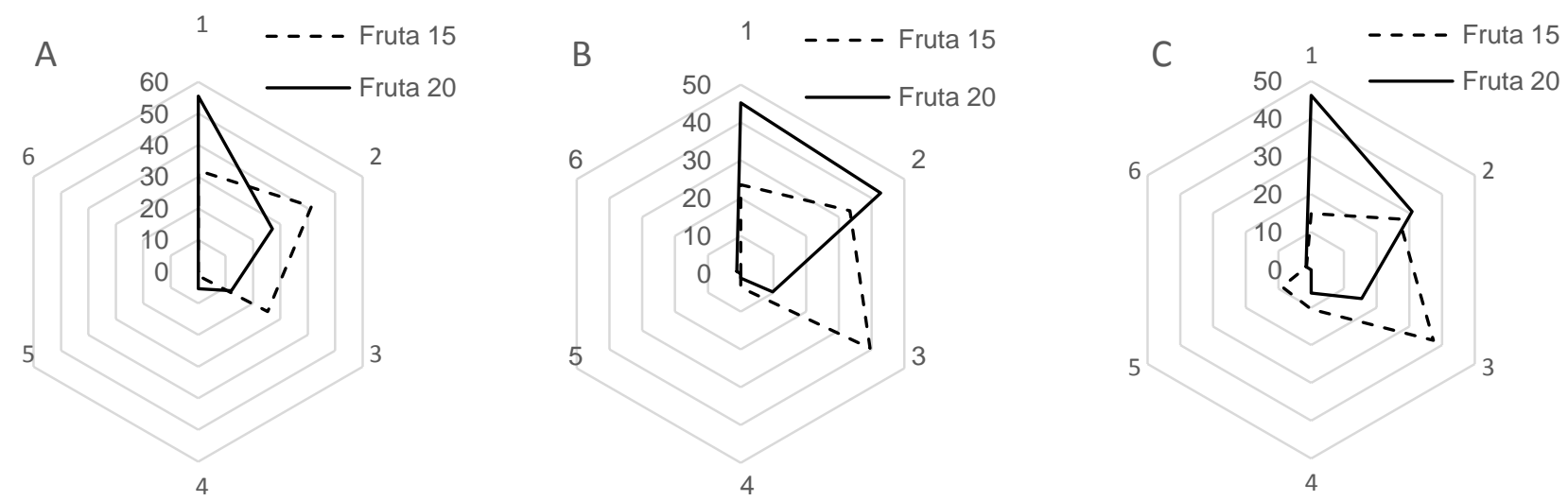

Fig. 3. Prueba de nivel de agrado para yogurt fortificado con 15 y $20 \%$ de almíbar de mortiño a los a) 0 días, b) 8 días y c) 16 días de almacenamiento. (1- Me gusta muchísimo, 2- Me gusta mucho, 3- Me gusta moderadamente, 4- Me disgusta moderadamente, 5-Me disgusta mucho, 6- Me disgusta muchísimo

\section{Propiedades probióticas}

La cantidad de unidades formadoras de colonia probióticas en el yogurt control y en las muestras tratadas en los días 0,8 y 16 de almacenamiento se reportan en la figura 4. Los resultados revelan que todas las muestras cumplen con la NTC 805 para designar alimentos probioticos que exige un conteo mínimo de $10^{6}$ UFC/mL después de 16 días de almacenamiento.

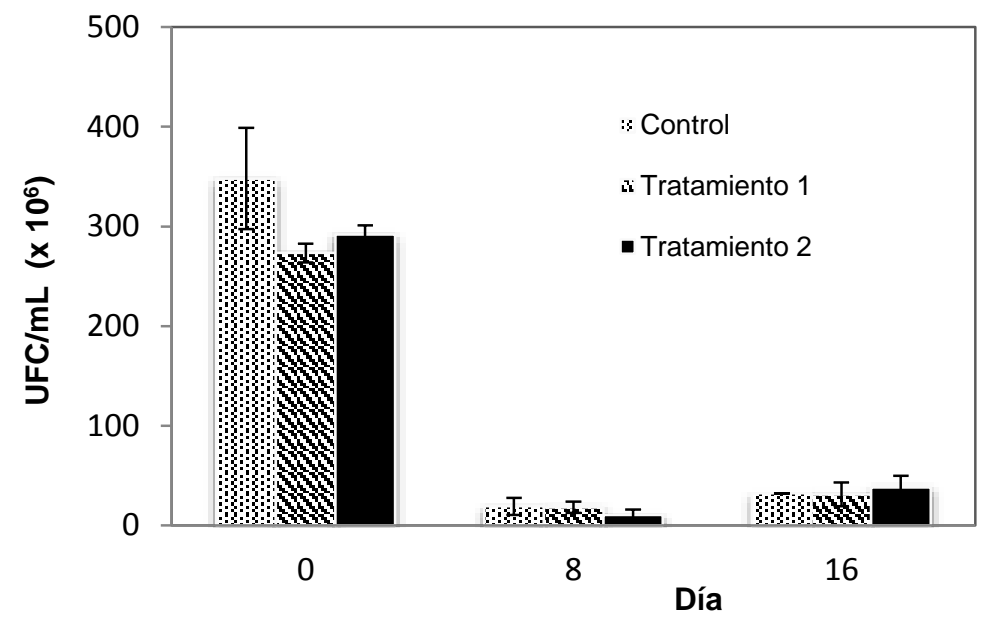

Fig. 4. Conteo de UFC probioticas / $\mathrm{mL}$ muestra del yogurt control y tratamientos 1 y 2 .

Aunque el producto control y tratado cumple con los requisitos para considerarse un producto probiótico, se observa una disminución significativa entre el conteo microbiológico del día 0 y el día 8 , pero luego un leve incremento para el día 16. Otros autores muestran diferentes tendencias en la viabilidad durante el almacenamiento, como lo es Ranadheera et al (2012) quien reporta una disminución, otros autores muestran un incremento seguido de un descenso (Guler-Akin y Akin. 2007). Estas diferencias pueden darse por los procesos de fabricación, condiciones de almacenamiento, como el empaque, ya que recipientes plásticos contribuyen a una viabilidad alta dada por una mejor permeación de oxígeno comparada con materiales cómo el acero que fue el material donde se guardó el yogurt de este ensayo, además también se pueden presentar diferencias en las tendencias por el uso de diversas cepas (Ranadheera et al., 2012). No obstante diversas investigaciones han revelado que esta cantidad de microorganismos probioticos es suficiente para ejercer una influencia positiva en la salud o en la fisiología del hospedero (Schrezenmeir y Vrese. 2001). Algunos beneficios incluyen mejoría en las enfermedades infecciosas, enfermedades crónicas intestinales como colitis ulcerosa, inmunomodulación, incremento en la biodisponibilidad de nutrientes, coadyuvante en enfermedades cardiovasculares, diabetes mellitus no insulinodependiente, obesidad, osteoporosis y cáncer (Shori, 2013).

\section{Propiedades antioxidantes}

La Figura 5 muestra los resultados de la capacidad antioxidante determinada mediante la técnica A) DPPH, B) FRAP y C) ORAC del yogurt control y tratado en los días $0,4,8,12,16$ y 20 de almacenamiento. Tanto para el control como para los tratamientos, el valor DPPH incremento entre los primeros 8 y 12 días de almacenamiento hasta valores máximos de $271,35,412,85$ y 265 umol trolox equivalente/L muestra para el 
tratamiento 1, tratamiento 2 y control respectivamente. Luego de estos días se evidenció un decaimiento del valor DPPH en todos los casos. Así mismo, para las muestras tratadas se presentó un incremento del poder reductor FRAP entre los primeros 8 y 12 días de almacenamiento hasta valores máximos de 148,42 y $163,99 \mathrm{mg}$ ácido ascórbico/L muestra para el tratamiento 1 y tratamiento 2 respectivamente, luego de estos días se evidenció un decaimiento del poder reductor para ambas muestras. En cuanto al control el poder reductor fue invariable en el tiempo, manteniendo valores alrededor de 19,96 mg ácido ascórbico/L muestra. El valor ORAC de las muestras tratadas incrementó entre los primeros 8 días de almacenamiento, hasta valores máximos de 3688,85 y 3992,96 umol trolox equivalente/L muestra para el tratamiento 1 y tratamiento 2 respectivamente, luego de estos días se evidenció un decaimiento de los valores para ambas muestras. En cuanto al control el ORAC fue invariable en el tiempo, manteniendo valores alrededor de 360,37 umol trolox equivalente/L.
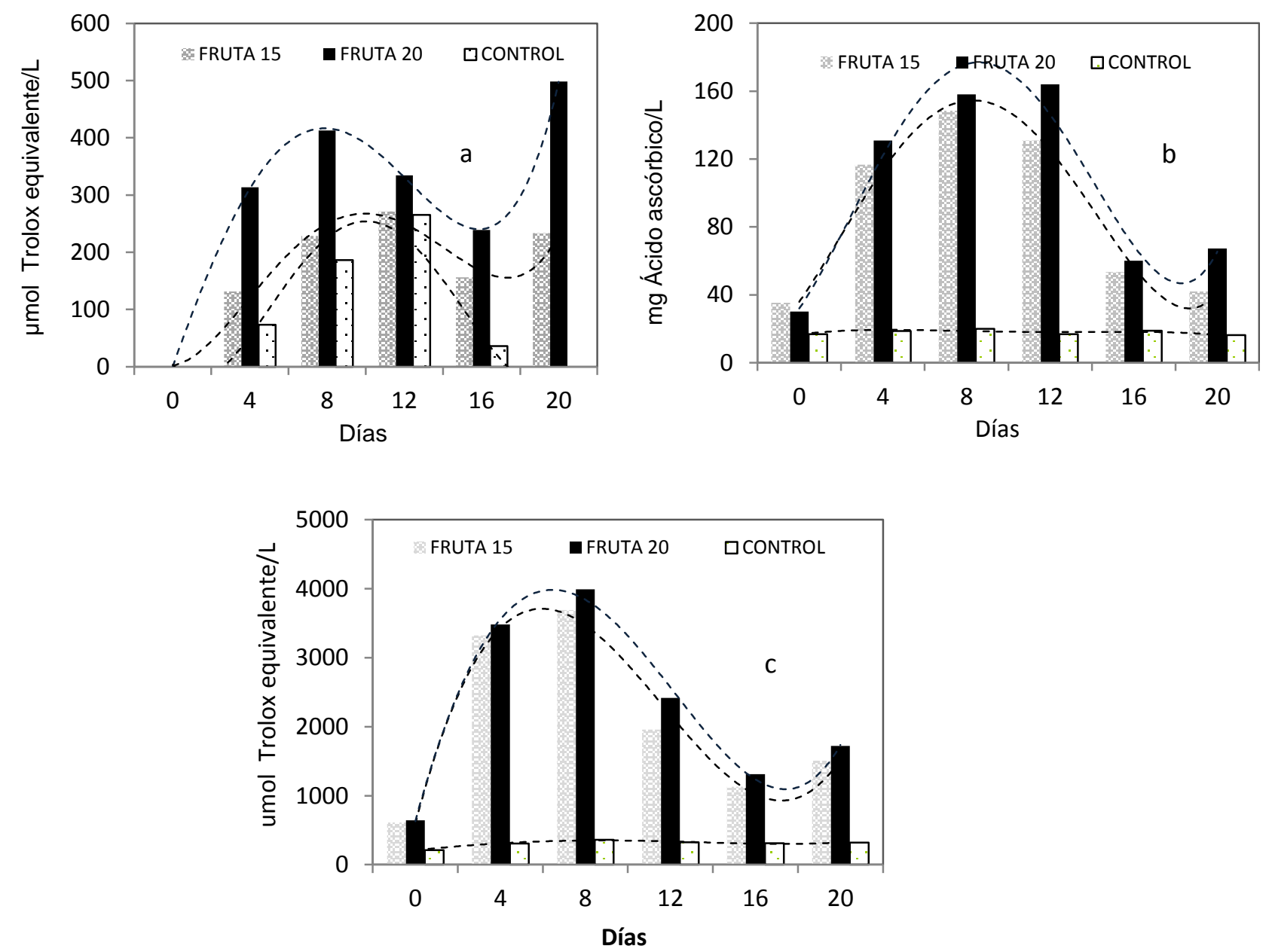

Fig. 5. Actividad antioxidante medida mediante las técnicas a) DPPH, b) FRAP y c) ORAC del yogurt con 15 y $20 \%$ de Fruta durante 20 días de almacenamiento a $4^{\circ} \mathrm{C}$

Todas las metodologías usadas revelaron que los valores de actividad antioxidante de las muestras tratadas son significativamente superiores a los valores arrojados para la muestra control, este resultado es coherente considerando que las muestras tratadas a diferencia del control están fortificadas con fruta que se comporta como fuente importante de compuestos polifenólicos que actúan como antioxidantes (Khan y Mukhtar, 2007; Petti y Scully, 2009). Se evidenció además un comportamiento particular en las muestras evaluadas; el incremento de la actividad antioxidante en los primeros días de almacenamiento (8 a 12) y el posterior descenso, para explicar esta tendencia es necesario observar el comportamiento de los metabolitos secundarios antioxidantes pues son ellos responsables directos de la actividad antioxidante total de las muestras debido a su capacidad para donar electrones y protones y con ello responder a las metodologías espectrofotométricas usadas (Zapata et al., 2013)

\section{Metabolitos antioxidantes}

El la figura 6 se muestra el contenido de A) Fenoles totales y B) Antocianinas totales del yogurt control y tratado para los días $0,4,8,12,16$ y 20 de almacenamiento. 

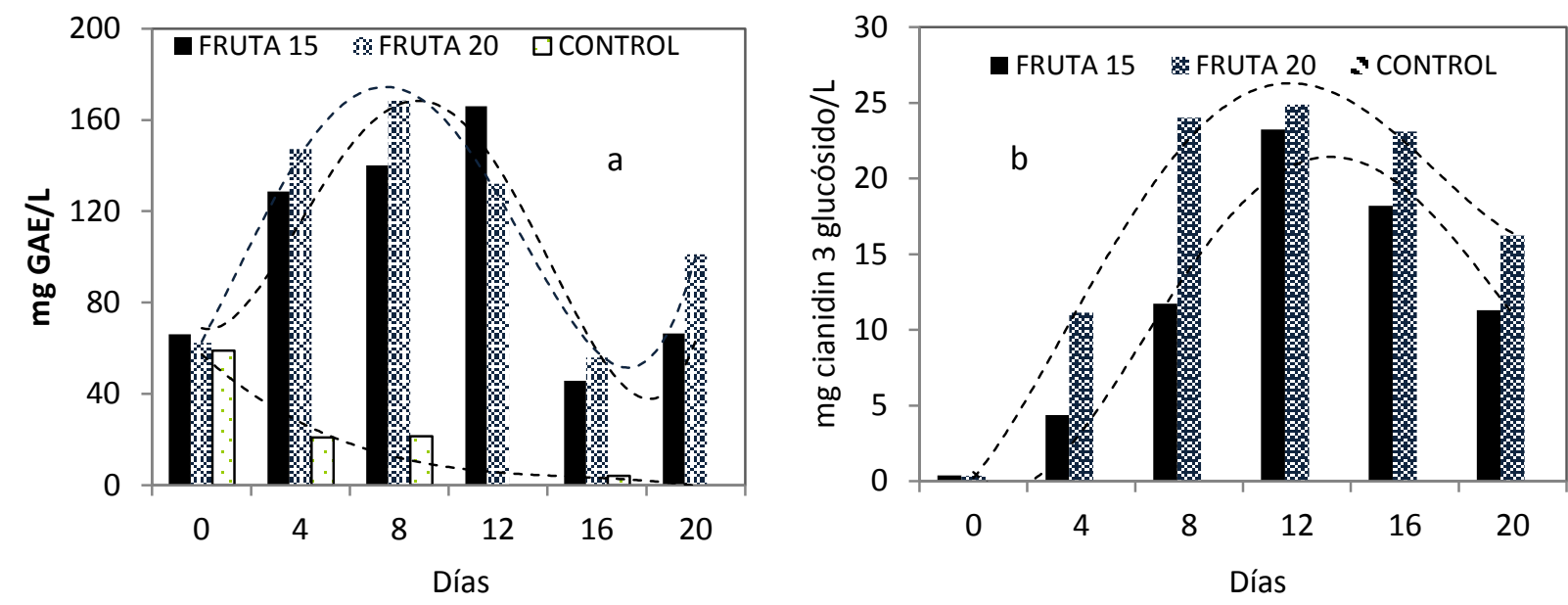

Fig. 6. Contenido de metabolitos secundarios a) Fenoles totales, b) Antocianinas totales del yogurt con $15 \mathrm{y}$ $20 \%$ de Fruta luego de $0,4,8,12,16$ y 20 días de almacenamiento a $4^{\circ} \mathrm{C}$

El contenido de fenoles totales presento diferencias estadísticamente significativas entre los tratamientos y el control, pero no entre muestras tratadas. Los valores de fenoles totales para el control son despreciables comparados con los valores arrojadas para las muestras tratadas, lo que es de esperarse considerando que la fuente mayoritaria de polifenoles en el yogurt es la fruta adicionada, la aparición de cierto contenido de fenoles totales en la muestra control se explica considerando la presencia de aminoácidos aromáticos endógenos como la tirosina que responden positivamente a la prueba de fenoles totales (Shah, 2000).

Para las muestras tratadas el contenido de fenoles totales incrementó entre los primeros 8 y 12 días de almacenamiento hasta valores máximos de 168.5 y $166.1 \mathrm{mg}$ Ácido gálico/L muestra para el tratamiento 1 y tratamiento 2 respectivamente, luego se evidencio un decaimiento del contenido fenólico. El evaluar el contenido de antocianinas en las muestras tratadas se determina el mismo comportamiento, es decir, ascendente en los primeros 8 a 12 días hasta valores máximos de 23.23 y 24,87 mg cianidin 3 glucósido/L muestra para el tratamiento 1 y 2 respectivamente y luego descendente.

Para ambos tratamientos existe una correlación positiva entre el comportamiento del contenido de antocianinas y el valor DPPH durante el almacenamiento (0,786 y 0,663 tratamiento 1 y 2 respectivamente), en este caso las antocianinas actúan neutralizando radicales mediante mecanismos SET favorecidos por la metodología DPPH (Prior et al., 2005). Para ambos tratamientos existe una correlación positiva entre el comportamiento del contenido de fenoles y el valor FRAP durante el almacenamiento $(0,92$ y 0,90 tratamiento 1 y 2 respectivamente). FRAP responde positivamente a polifenoles antioxidantes y a sustancias reductoras como azúcares simples que nada tienen que ver con la actividad antioxidante. Las correlaciones revelan que en este caso el poder reductor es otorgado por los polifenoles, verdaderos antioxidantes, y no por azúcares reductores que conducen eventualmente a falsos positivos. Finalmente existe una correlación positiva entre el comportamiento del contenido de fenoles y el valor ORAC durante el almacenamiento para ambos tratamientos $(0,71$ y 0,96 tratamiento 1 y 2 respectivamente). Se sabe que las metodologías FRAP y ORAC son mecanismos SET y HAT respectivamente (Prior et al., 2005), debido a que el contenido fenólico guardó una relación estrecha con ambas metodologías, puede concluirse que los metabolitos de la muestra tienen capacidad para neutralizar radicales libres cediendo un electrón o bien un átomo de hidrogeno.

El comportamiento particular de las propiedades antioxidantes y el contenido polifenólico ha sido evidenciado en diferentes investigaciones. Varias estudios han hallado un incremento en el contenido fenólico con el consecuente aumento de la actividades antioxidante de alimentos nutracéuticos almacenados, algunas de las explicaciones al respecto, se presentan a continuación: 1) efecto relacionado con una mayor producción de azúcares reductores durante el almacenamiento a lo que se refieren como "edulcorante en almacenamiento", y que son estos utilizados como sustratos para la síntesis de compuestos polifenólicos futuros aumentó en la actividad fenil alanina monoliasa, que se traduce en un incremento en la concentración de compuestos polifenólicos libres, junto con el bajo nivel de actividad polifenoloxidasa que pueden reducir la oxidación de sustratos fenólicos a quinonas. Incremento de los compuestos polifenólicos y otros componentes bioactivos en respuesta al estrés provocado durante el almacenamiento, se cree que las muestras vegetales comienzan la producción de glicoalcaloides y fenoles (Ginzberg et al., 2009) algunos ácidos fenólicos como el p-coumárico y felúrico durante el almacenamiento, pueden ser liberados de su forma enlazada o esterificada, gracias a la variación en el pH a causa de la acción bioquímica y microbiológica (Ginzberg et al., 2009). 


\section{CONCLUSIONES}

Se concluye que el producto elaborado es un alimento nutracéutico, con efecto nutritivos y beneficioso sobre la salud humana expresados por poder probiótico y antioxidante. Ademas, se establecen los primeros 8 días desde su elaboración como momento adecuado para el consumo, tiempo donde se presentan el mayor conteo microbiológico, la mejor actividad antioxidante y la menor proporción de cambios fisicoquímicos.

\section{REFERENCIAS}

A.O.A.C., 1996. 942.15. Official Methods of Analysis, $14^{\text {th }}$ ed. Association of Official Analytical Chemists, Washington, D.C.

Abdel-Rahman, M. A., Y. Tashiro y K. Sonomoto, Recent advances in lactic acid production by microbial fermentation processes, Biotechnology Advances: 31 (6), 877-902 (2013).

Amirdivani, S. y A.S. Baba, Changes in yogurt fermentation characteristics, and antioxidant potential and in vitro inhibition of angiotensin-1 converting enzyme upon the inclusion of peppermint, dill and basil, $L W T-$ Food Science and Technology: 44 (6), 1458 - 1464 (2011).

Eissa E.A. y otros cuatro autores, Physicochemical, microbiological and sensory characteristics of yoghurt produced from camel milk during storage, Electronic Journal of Environmental Agricultural and Food Chemistry: 10 (6), $2305-2313$ (2011).

Eyéghé-Bickong, H.A. y otros cuatro autores, Optimisation of an HPLC method for the simultaneous quantification of the major sugars and organic acids in grapevine berries, Journal of Chromatography B: 885- 886 (15), $43-49$ (2012).

Gaviria, C. y otros cuatro autores, Cambios en la Actividad Antioxidante en Frutos de Mortiño (Vaccinium meridionale Sw.) durante su Desarrollo y Maduración, Rev. Fac. Nal. Agr. Medellín: 65 (1), 6487 - 6495 (2012).

Ginzberg, I., J.G. Tokuhisa y R.E. Veilleux, Potato steroidal glycoalkaloids: Biosynthesis and genetic manipulation. Potato Research.: 52 (1), 1 - 15 (2009).

Guler-Akin, M. B. y Akin, M. S. Effects of cysteine and different incubation temperatures on the microflora, chemical composition and sensory characteristics of bio-yogurt made from goat's milk. Food Chemistry: 100(2), 788-793 (2007).

Illupapalayam, V.V., S.C. Smith y S. Gamlath, Consumer acceptability and antioxidant potential of probioticyogurt with spices, LWT - Food Science and Technology: 55 (1), 255-262 (2014).

Khan, N. y H. Mukhtar. Tea polyphenols for health promotion, Life Sciences: 81(7), 519-533 (2007).

Lopera YE y otros 6 autores. Antioxidant Activity and Cardioprotective Effect of a Non-Alcoholic Extract of Vaccinium meridionale Swartz During Ischemia-Reperfusion in Rat. Evid Based Compl Alt. 1-31(2013).

Maldonado ME, Arango-Valera SS, Rojano, B. Radical scavenging, cytotoxic and proliferative effects of Vaccinium meridionale in human colon cancer lines. Revista cubana de Plantas Medicinales, 19 (2), 1-15, (2014).

Novakova, L., P. Solich y D. Solichova, HPLC methods for simultaneous determination of ascorbic and dehydroascorbic acids, Trends in Analytical Chemistry: 27 (10), 942 - 958 (2008).

Ostlie, H., M. H. Helland y J. Narvhus, Growth and metabolism of probiotics in fermented milk, International Journal of Food Microbiology: 87, 17 - 27 (2003).

Petti, S. y C. Scully, Polyphenols, oral health and disease: A review. Journal of Dentistry: 37(6), 413-423 (2009).

Prior, R.L., X. Wu y K. Schaich, Standardized methods for the determination of antioxidant capacity and phenolics in foods and dietary supplements, Journal Agriculture Food Chemistry: 53 (10), 4290-4302 (2005). 
Ranadheera, C. S., Evans, C.A., Adams. M.C. y Baines. S.K. Probiotic viability and physico-chemical and sensory properties of plain and stirred fruit yogurts made from goat's milk. Food Chemistry: 135, 1411-1418 (2012).

Rodriguez, R. y otros 6 autores, Use of Raman spectroscopy to determine the kinetics of chemical transformation in yogurt production, Vibrational Spectroscopy, 68, 133-140 (2013).

Sah, B.N.P. y otros cuatro autores, Effect of probiotics on antioxidant and antimutagenic activities of crude peptide extract from yogurt, Food Chemistry: 156 (1), $264-270$ (2014).

Sakai, T.y otros 7 autores, M-RTLV agar, a novel selective medium to distinguish Lactobacillus casei and Lactobacillus paracasei from Lactobacillus rhamnosus, Int. J. Food Microbiol: 139 (3), 154 - 160 (2010)

Schrezenmeir, J. y M. De Vrese, Probiotics, prebiotics and synbiotics: Approaching definition, American Journal of Clinical Nutrition: 73, 361S - 364S (2001).

Shah N.P., Some beneficial effects of probiotic bacteria, Bioscience Microflora: 19, 99 - 106 (2000).

Shori, A.B., Antioxidant activity and viability of lactic acid bacteria in soybean-yogurt made from cow and camel milk. Journal of Taibah University for Science: 7 (4), 202 - 208 (2013).

Watts, B., Ylimaki, G., Jeffery, L., \& Elías, L. (1992). Métodos sensoriales básicos para la evaluación de alimentos. Ottawa, Canadá: International Development Research Centre.

Zapata, K., B. Cortes y B.A. Rojano, Polifenoles y Actividad Antioxidante del Fruto de Guayaba Agria (Psidium araca), Información tecnológica: 24 (5), 103 - 112 (2013). 
